\title{
Using Personal Information Management to Strengthen Information Literacy at Work
}

\author{
Abdus Sattar Chaudhry, Sajjad ur Rehman, Lulwh Al-Sughair \\ Kuwait University
}

\begin{abstract}
Personal information management (PIM) practices of 83 knowledge workers from 11 companies in Kuwait were surveyed focusing on finding; organization \& management; and re-finding of information. Results indicated that information was gathered from a variety of sources for performing tasks at hand. About more than 50\% of it was also kept for future use. Employees saved this information on desktops and hard drives and also used Favorites and Bookmarks to facilitate its refinding. They used different work related categories to organize information in folders. They regularly updated their files and folders and also used tools to support PIM activities. Awareness needs to be created about knowledge organization schemes such as personal taxonomies and categorization to better organize e-documents in personal collections. Enhanced information literacy training with appropriate integration of PIM skills will improve information finding and re-finding to help exploit digital information more effectively.
\end{abstract}

\section{Introduction}

With the explosion of digital information, electronic publishing, and web-based information sources, knowledge workers are overwhelmed with the amount of information they receive and collect from a variety of sources and channels. A major portion of this information can be kept for future use, in addition to performing tasks at hand. However, if proper steps are not taken to organize and manage this information, employees are unlikely to find the needed information in timely manner to meet their immediate information needs. Certain useful information may be even lost forever. This also create information overload resulting in frustration. Employees will have to take steps for more efficient information management to strengthen their finding and re-finding capabilities for effective exploitation of digital information.

Several studies have indicated that companies lose considerable financial resources as a consequence of knowledge workers not being able to find information from their own folders. It has been pointed out that finding information is difficult for the first time but it is even more difficult the second time. Efficient information management behavior has been suggested as a good strategy to overcome this problem. It is important to investigate how employees in different organization organize and manage information to suggest measures to improve information finding and re-finding.

We conducted a study to review the practices used by corporate sector employees in Kuwait for managing e-documents they collect from a variety of sources. The study was aimed at developing an understanding of personal information management (PIM) skills and related issues. The study was guided by the following research questions:

- What sources are used for information gathering by professional staff in the corporate sector?

- What methods are used for saving and archiving information for future use?

- What techniques are used for organizing digital resources in personal archives?

- What information behavior exists among the private sector employees for managing and updating information?

- What tools are used by private sector employees to support personal information management activities?

- What strategies are deployed for re-finding information by private sector employees?

- What difficulties are experienced by private sector employees in re-finding information?

Based on results of the study, steps have been recommended to enhance personal information management skills of employees working in private companies in Kuwait.

\section{Conceptual Framework}

Earlier studies of information behavior have focused more on information seeking and use. For example, Doyle looked at information seeking as part of information literacy [1]. Wilson defined information behavior as the totality of human behavior in relation to sources and channels of information, including information seeking and information use [2]. Choo et al. described three components of information behavior: information 
needs, information seeking, and information use [3]. Their study focused on use of information by managers and highlighted trends in using web-based information. God bold presented a general model for information seeking and highlighted series of steps considered important in making information searching more effective [4]. Case asserted that information behavior encompasses information seeking as well as other unintentional or passive behaviors [5].

This study goes beyond information seeking. It looks at information behavior with an intention to cover steps after the information has been sought, focusing on personal information management practices. In this study, the term personal information is used in the sense that the documents are owned by the knowledge workers and are under their direct control [6], not that they necessarily contain information about the persons (knowledge workers) [6]. Similarly, the term management is not used in, this paper, in the business sense. It refers to activities that are carried out to make sense of information for its possible application in work. Lansdale states that personal information management (PIM) refers to the practice and the study of activities people perform in order to acquire, organize, maintain, retrieve and use information items such as paper-based and digital documents, web pages and email messages for everyday use so as to complete work-related and other tasks [7]. PIM in this paper is used to describe the collection, storage, organization and re-finding of items of digital information (e.g. email, files, appointments, reminders, contacts, bookmarks) by an individual in their personal computing environment [7]. Bergman et al. compared PIM with general information management in which a professional - such as a librarian - manages information for other people [8]. In contrast, with PIM the onus is on an individual to manage his/her own information.

The abundance of digital resources is creating challenges in finding and re-finding information. Capra, Pinny, and Pérez-quiñones pointed out that needs to store, re-find, and re-use electronic information are not well understood and supported by the existing interfaces and retrieval systems [9]. Most people can easily find the needed information using the web but it is difficult for them to relocate the information which is already found.

Barth suggested that the most effective strategy in managing personal information and knowledge in the digital environment would be development of self-organization competencies among employees, knowledge workers, and professionals [10]. Suggested that regularity in cleaning electronic files and categorizing information resources in appropriate folders would be helpful in overcoming the information overload in the digital environment [11].
More efficient information management practices will be required to enhance finding and re-finding of information in the digital environment. Rowlands et al. remind us for a need of improved information literacy among professionals and knowledge workers [12]. They alert that a fundamental shift in the way people seek and read information has already occurred and that the impact of the shift has yet to be understood by information providers and educators.

Chaudhry stated that proper information management helps control information overload and facilitate future finding of the information within a short timeframe [13]. Organizational schemes such as personal taxonomies help organize e-document location in personal collections Chaudhry reported that public sector employees in Kuwait leveraged these schemes for developing and managing their personal networks [14].

Tools and technologies can assist in organizing and managing digital resources if professionals are equipped with the right competencies. PIM tools play an important role in managing e-documents, files, emails, and bookmarks. highlighted that the proper usage of these tools will lead to quicker finding of information in a short amount of time and with less effort [15]. Majid et al. stated that these tools help properly manage, organize, and recall the stored information [16]. Simple tools and services are available to handle different information types and formats, e.g., Flicker, Outlook, and YouTube [16]. Pointed out that one possible solution to overcome the problem of overload of information is to store information online using clouds and outside sources [17]. They highlighted that keeping information in such sources can help overcome the problem of information overload and information fragmentation.

Information literacy skills are considered important for handling information. Some studies have discussed the connections between information literacy and information management, [18], [19], [20] have addressed the various issues involved information literacy training. Traditional models of information literacy focused more on searching information [10]. In the digital environment patterns of information finding have changed. Most professionals now find information themselves. In addition, information is pushed to them from other sources - sent unsolicited. In this framework, it is not the finding that is important, organizing and managing of what is found have become even more important to reduce the information overload and save time through efficient re-finding. There is also a need for guidelines for better handling of edocuments, archives, records, and other vital information resources.

Information overload occurs when users do not have enough time to read, understand, and utilize the available information. Information overload can even 
cause information anxiety, which may result in frustration, hypertension, distraction, confusion, helplessness, irritation, and annoyance. Training in personal information management can help overcome information fragmentation problems [20]. Company time wasted when employees are able to find relevant information quicly.

O'Farrill highlights that information literacy IL and PIM) are two closely related and overlapping concepts [19]. However, most of the existing IL models and standards do not put adequate emphasis on relevant PIM skills. In our view, proper integration of PIM techniques and tools into IL skills is likely to strengthen competency level of an information literate person (knowledge worker), resulting in saving time, effort and resources. This integration can also help overcome the problems of information overload and information fragmentation.

This paper argues that information literacy training programs need to expand their scope by incorporating appropriate PIM skills to provide a more comprehensive skill set to employees, professionals, and knowledge workers. This view is portrayed in Figure 1.

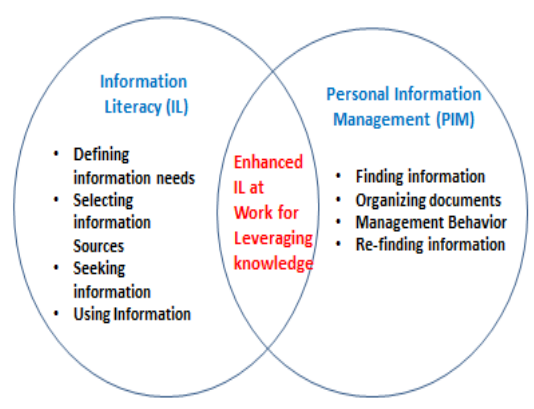

Figure 1. Integration of II and PM to support KM

\section{Methodology}

A web-based questionnaire was used for collecting data on different aspects of personal information management. Data for this study was collected from professionals and managers from selected companies in Kuwait. An email was sent to all major companies in Kuwait identified from major company directories. Top 10 companies were selected randomly from three major directories. More than a hundred employees filled-in the questionnaires, out of which only 83 questionnaires were usable.

Part 1 of the questionnaire contained closed questions. In these questions, we asked respondents to choose from the options provided. Part 2 contained open-ended questions. In these questions, participants could provide information without being restricted to listed options. This structure was useful in gaining deeper insights and seeking rich information to aid in the discussion of results and to put the findings into a proper context.

As contact details of company employees were not included in the directories, we requested the companies to distribute the questionnaire to all employees who held a minimum educational qualification of a bachelor's degree and were doing professional work in their area of specialization. This criterion was consistent to the definition we used for a knowledge worker. In this paper, we have used the term employees, professionals, and knowledge workers interchangeably.

The majority of the professionals who responded to the questionnaire $(60 \%)$ were females; $36 \%$ of them were under the age of $30 ; 52 \%$ hold a bachelor's degree and have less than five years of work experience. The participants were from 17 companies from the following sectors: Furniture and Household (28), Telecommunications (20), Information Technology (10), Banking and Insurance (7), Oil (1), Law (1), and miscellaneous businesses (7). Specific position titles of respondents included lawyers, architects, financial managers, CEO, sales officers, design engineers, security supervisors, public relations officers, bank supervisors, interior designers, group leaders, accountants, brand executives, financial analysts, editors, managers, coordinators, hardware specialists, network administrators, IT specialists, training supervisors, security engineers, and logistic planners.

\section{Findings}

Information Sources-Participants reported that they were collecting and receiving work related information from a variety of sources. Table 1 shows the frequently used sources arranged by number of responses.

As expected, the top source for collecting or receiving information turned out to be the company sources, websites, social media, and external websites. Participants reported the following as most trusted sources: Google (32), Websites (9), Company websites (7), Wikis and blogs (4), Academics, experts, and senior colleagues (3).

The following sources were considered most reliable:

- Company sites/sources (10)

- Google (10)

- Websites (7)

- Vendors and manufacturers (6)

- YouTube (3)

- Wikipedia (2) 
Table 1. Sources Used for Gathering Information $\mathrm{N}=83$

\begin{tabular}{|l|c|c|}
\hline Source & Frequency & $\%$ \\
\hline $\begin{array}{l}\text { Company sources } \\
\text { (portal, intranet, website, } \\
\text { repositories, etc.) }\end{array}$ & 27 & 32.53 \\
\hline $\begin{array}{l}\text { Social media and } \\
\text { software (Facebook, } \\
\text { Twitter, LinkedIn, } \\
\begin{array}{l}\text { Instagram,WhatsAppBlo } \\
\text { gs, Wikis) }\end{array}\end{array}$ & 22 & 26.50 \\
\hline $\begin{array}{l}\text { Websites (accessed } \\
\text { through search engines, } \\
\text { e.g., Google, Yahoo) }\end{array}$ & 20 & 24.10 \\
\hline $\begin{array}{l}\text { Instant messages } \\
\text { (Windows, Yahoo, } \\
\text { Google, etc.) }\end{array}$ & 10 & 12.05 \\
\hline E-mail attachments & 4 & 04.82 \\
\hline
\end{tabular}

Google is not a source of information. It is a search engine (which can be considered an index). In other words when employees list Google they actually mean a website.

It is obvious from the responses that company sources are very valuable for knowledge workers as these were listed as reliable by most and were also the second highest frequently used and most trusted. We asked the respondents what features in company sites were considered the most useful. The following features were listed by the participants: Search Box (10), About Us (8), Organizational Facebook (6), Help (5), and Contact Us (3).

Most employees in private companies were confident in selecting appropriate sources for finding information related to a task at hand. They were also able to elicit relevant information from specialized sources and could comfortably assess the quality of information found. The following statements reflect their perceptions about information finding skills:

1. Most knew when to use web and when to use specialized sources.

2. They were able to select the right information from specialized sources.

3. They were able to assess the quality of information reasonably well.

4. They could distinguish between views, opinion, facts, advocacy, etc.

5. They were always able to ask focused questions.

6. They could integrate and synthesize information from various sources to create new knowledge.

The participant reported that more than $50 \%$ of edocuments gathered were considered useful for future use. They reported that when the gathered information was perceived as useful for performing current tasks, they consumed it immediately. For information items which could be potentially useful in future, they considered several factors in making the decision to keep it for future use. Factors considered in their decisions including the following:

- Effort needed to store it

- Repercussions if it is not stored but might be needed in future

- Best ways to store it for future re-finding

- Preferred location and device to save it on

- Reasons for keeping it (possible potential use)

- Expected useful life of the stored information

Participants reported that the most favored method to keep information for future use was bookmarking followed by saving information in folders or drives. Other methods used for keeping information for future use are listed below:

- Linking through Bookmarks and Favorites

- Saving on desktop and share drives

- Emailing to yourself

- Storing on outside services

- Pasting the web address (URL) into a document

In response to an open ended question, respondents reported that more appropriate methods to get back to the information saved were: Browsing History (5), Keyword Searching (5), Searching in Google (3), and using Bookmarks (2).

It was, however, interesting to note that the choice of methods for saving and keeping information by knowledge workers in the private sector is different from that of their counterparts in the public sector. A recent study reported that knowledge workers in the public sector of Kuwait were not making a good use of bookmarks for saving information $[13 ; 14]$.

Folders appear to be the most popular method. It is therefore important that files are named in a logical way and folders are structured using intuitive category levels. Otherwise, there is a danger that these documents buried in folders are difficult to retrieve when needed. The next section describes the methods and categories used by employees for organizing their e-documents.

\subsection{Organizing E-documents}

Employees were asked what categories they used to name folders in which they saved information. Organization structure (department, functions, etc.) was listed as the most frequently used category to organize information folders. Other types of methods used are listed below:

- File format

- Geographic region

- Subject 
- Project

- $\quad$ Status/version

We noticed that employees in the private sector institutions were not aware of knowledge organization schemes such as taxonomies and categorization schemes. Since folders are used as the most frequently used method to keep information that might be needed in future, it is important to introduce the concepts of personal taxonomies and tagging information items to professionals in the private sector. Chaudhry suggested using shared folders to improve personal information management and developing guidelines for labeling and naming documents and structuring folders [13 \& 14].

\subsection{Managing Information}

Questionnaire contained a series of statements about personal information management behavior. Participants were asked to choose the statements that reflected their behavior the best.

About $25 \%$ of the respondents reported they cleaned their files and folders as and when needed while another $25 \%$ indicated that they did that when documents were no longer needed in their view. Only $15 \%$ reported that they were cleaning their desktop on a regular basis.

Based on the responses to the questions related to the information management behavior, their behavior could be categorized into the following groups:

- Filers: they used structured approach for organizing their documents based on certain attributes (e.g. activities/tasks, subjects, projects, format, and status).

- Pilers: they kept piling up documents without using any schema or structure.

- Spring cleaners: they did not use a filing system all the time but periodically attempted to organize information items based on certain attributes.

It was reported that filers were able to retrieve the stored documents with less time and effort. However, when information was in different locations, formats, and devices; fragmentation of information restricted its re-finding. They did not restrict their use of computer to just one machine. They used a desktop computer at work, a laptop at home, a smart phone or tablet when on the move.

Information management varies according to individual work style. It is therefore not easy to control. Careful steps need to be taken by companies to inculcate a work culture where reminders are issued and procedures are put in place encouraging deleting documents, cleaning files, and updating documents on regular basis. Support staff may be assigned to visit professionals to review their files and folders and assist in maintaining information files and folders.

\subsection{Use of Tools}

Technologies and tools help professionals spend less time on labor-intensive and error-prone personal information management activities. Use of smart technologies can enable knowledge workers to make creative and intelligent use of the information at hand. There are plenty of tools currently available as part of enterprise portals and information systems. We asked the participants to list the types of tools they frequently used. We asked them to mention specific tools only as examples.

The following specific tools were listed by participants: Calendars, tasks, schedules,; iSpace; Enfish; 7sDoc; Copernic, Google Desktop, LesTec, Mybase, Xboni, and Liaise.

Social media was listed among the top information sources for collecting and receiving information in an earlier question (i.e., information sources used). In the open-ended questions, we asked participants to list specific social media and social software they use frequently in the course of their work.

LinkedIn was the most frequently used social networking forum by knowledge workers in the Kuwaiti private sector. It is interesting to note that in an earlier study of social media use in Kuwait's public sector, LinkedIn was the least frequently used networking tool [13]. Social media has become crucial in exploiting personal information. In addition to keeping contacts and networking with professional colleagues, social networking sites also serve as major sources of information. As reported in the section on information finding, social media and social software were considered among the top information sources preferred by participants.

In response to an open-ended question, participants reported use of the following applications of social media within their companies: Marketing (3), Notifications and Announcements (3), Getting Connected (3), and Feedback from Customers (2).

Employees in the Kuwaiti corporate sector were using email and PIM tools to organize and maintain their personal archives and collections of documents. But they were not able to control the fragmentation of information. They considered information fragmentation as a major problem in re-finding information. This has been highlighted in the professional literature. Studies have reported the use of multiple devices for keeping and organizing information may lead to information fragmentation [17], [18]. It was reported that even within the same device, information was scattered into different files, folders, and incompatible application software [19]. It has been emphasized that proper information 
management behavior and use of simple tools can help overcome these difficulties [20].

We asked the participants what actions they take to make sure that emails are managed effectively. While $21.68 \%$ of participants reported that they generally leave everything in the inbox, $20.48 \%$ reported that they used folders to structure archived messages. Another $20.48 \%$ reported that they periodically review message to delete unnecessary communications. In a subsequent open-ended question, participants were also asked what features were important in an email system. They listed the following features: Folders (12), Archiving (5), Categorization (3), Search (2), Task and Calendars (2), Address and Signature (2), and Mail Forwarding (1). It is important that email systems used in organizations have easy-to-use mechanisms for all of these features.

Employees in private companies in Kuwait appeared to be aware of the need to identify personal contacts in an effort to build and maintain personal contacts. Email is among their preferred methods for building contacts. Other sources used included social media and networking tools.

\subsection{Re-finding of Information}

Information re-finding is a more directed and targeted search task than information finding. Finding information is an exploratory activity that involves recognition, while re-finding information is a focused task which involves both recognition and recall [9].

We presented 10 statements about information refinding approaches to seek input from the participants of this study. Table 2 shows use frequency of various approaches that the knowledge workers in the private sector of Kuwait used.

Table 2. Approaches for Re-Finding Information $\mathrm{N}=82$

\begin{tabular}{|c|c|c|c|}
\hline$\#$ & Strategy & Frequency & Percentage \\
\hline 1 & $\begin{array}{l}\text { Searching by } \\
\text { keywords }\end{array}$ & 31 & 37.80 \\
\hline 2 & $\begin{array}{l}\text { Browsing through } \\
\text { folder structure (by } \\
\text { names of folders } \\
\text { and files) }\end{array}$ & 16 & 19.51 \\
\hline 3 & $\begin{array}{l}\text { Access through } \\
\text { bookmarks }\end{array}$ & 13 & 15.85 \\
\hline 4 & $\begin{array}{l}\text { Search the file } \\
\text { names by } \\
\text { remembering tags or } \\
\text { labels }\end{array}$ & 11 & 13.41 \\
\hline 5 & $\begin{array}{l}\text { Prefer to use } \\
\text { memory }\end{array}$ & 7 & 8.53 \\
\hline 6 & $\begin{array}{l}\text { Scan the desktop } \\
\text { screen }\end{array}$ & 4 & 4.87 \\
\hline
\end{tabular}

Folders are the most frequently used means for re-finding information. Other methods used by the respondents included the following:

- Searching in Google (3)

- Reviewing History (5)

- Keyword searching (5)

- Bookmarks (2)

It was reported in an earlier section of this paper that folders were also reported as the most popular method of saving information. As stated above, these are also preferred for information re-finding by private sector employees. It is therefore desirable that proper attention is paid to develop guidelines for naming files and structuring folders. For making this easy to use, these names and tags can be provided in the company information systems as pull-down menus and sub-directories. There are simple tools available for structuring folders for email and documents as well as information items in personal collections. These features can also be integrated in the enterprise information systems used by private sector organizations.

The lack of proper information management behavior results in information overload and subsequently affects information re-finding. This problem is further aggravated due to easy access to tremendous amounts of information through multiple devices. Majid et al. [17] highlighted that each new technology is making it further easier and less costly to produce, acquire and disseminate information, adding to the existing information overload. Information overload occurs when employees do not have enough time to read, understand, and utilize the available information. This creates frustration when information re-finding is not successful. This can cause anxiety, which may result in hypertension, distraction, confusion, helplessness, irritation, and annoyance [18]. It also affects the performance of employees and results in wastage of organization resources.

\section{Conclusions}

Knowledge workers in Kuwaiti companies are overwhelmed by the amount of information they collect and receive from a variety of sources. Most employees were confident in searching information and considered their information finding skills satisfactory. A considerable amount of information is sent to them (pushed) unsolicited. Review of information management practices indicated that they are relying heavily on information collected through, company sources, social media, and websites. Participants also reported that a big chunk of information is kept for future use. The most preferred methods to save information included 
bookmarks or favorites and saving information in folders. Most participants appeared to be well informed about the need for organizing the saved documents. The most favored categories used to organize information in folders included department/function, document type and file format.

Information management behavior of study participants was found encouraging as a majority of them reported that they regularly cleaned their desktop, filed documents into folders on weekly basis, and deleted files/folders when there was no use for the information they kept. Their information management behavior can be categorized as filers, pilers, and spring cleaners.

Employees also expressed satisfaction on the approaches used for re-finding information from their personal collections and archives. Folders were the most frequently used means for re-finding information. Searching by keywords and accessing information through bookmarks were also listed as frequently used strategies for re-finding of information already found. However, strategies of refinding of information are desired to be review to make it more effective. There is also a need to create awareness about the importance of schemes such as personal taxonomies and tree structures to facilitate locating e-documents in personal collections.

Most frequently used tools for managing information included personal information management tools, email management tools, and search tools. Concept and mind mapping tools were not frequently used. Social media and networks were used for marketing, announcements, and feedback from customers, while blogs and wikis were not as frequently used. Potential of social media can be explored further particularly for building personal networks.

We recommend that training programs are conducted to enhance information literacy (IL) at work to enhance information finding and re-finding capabilities of employees. We also recommend that this training should incorporate personal information management. A review of existing IL standards indicates a gap or inadequate emphasis on the management of gathered information [17].

Majd et al. [18] suggest that a thoughtful integration of IL skills with appropriate PIM techniques is likely to save time, money, energy and efforts of employees. An incorporation of selected PIM techniques and tools into IL training can significantly improve its impact and benefits. We, therefore, recommend that companies arrange IL training and expand the scope of their IL training programs by including certain PIM techniques, particularly dealing with information organization and management. This way they can empower their employees with more skills to effectively perform their job and ultimately contribute to the organizational effectiveness.

\section{References}

[1] Doyle, C. S. (1994). Information literacy in an information society: A concept for the information age. New York: ERIC Clearinghouse on Information and Technology, Syracuse University, 1994.

[2] Wilson, T. D. (2000). Human Information Behavior. Informing Science, 3(2), 49-55.

[3] Choo, W., Detlor, B., \& Turnbull, D. (2000). Web Work: Information Seeking and Knowledge Work on the World Wide Web. Dordrecht: Kluwer Academic Publishers.

[4] Godbold, N. (2006). Beyond information seeking: Towards a general model of information behaviour. Information Research, 11(4). (March, 12, 2014), from http://InformationR.net/ir/11-4/paper269.html Wilson, T. D. (2000). Human Information Behavior. Informing Science, 3(2), 49-55.

[5] Case, O. (2007). Looking for Information: A Survey of Research on Information Seeking, Needs, and Behavior $\left(2^{\text {nd }}\right.$ ed.). Amsterdam: Academic Press.

[6] Boardman, R. \& Sasse, M. (2004). Stuff goes in to the computer and doesn`t come out: a cross-tool study of personal information management.

[7] Lansdale, M. (1988).The psychology of personal information management. Applied Ergonomics, 19, 55-66.

[8] Bergman, O., Marom, R. B., Nachmias, R., Gradovitch, N., and Whittaker, S. 2008. Improved search engines and navigation preference in personal information management. ACM Transactions on Information Systems, Vol.26, no.4, doi:10.1145/1402256.1402259.

[9] Capra, R. G., \& Pérez-quiñones, M. A. (2006). Factors and evaluation of re-finding behavior. SIGIR Workshop on Personal Information Management, Seattle, Washington.

[10] Barth, S. (2004). Self-organization: taking a personal approach to KM. In Knowledge Management Tools and Techniques: Practitioners and Experts Evaluate KM Solutions, Rao, M. (ed.). Butterworth-Heinemann: Boston, MA.

[11]. Khoo, C., Luyt, B., Ee, C., Osman, J., Lim, H.H. \& Yong, S. (2007). How users organize electronic files on their workstations in the office environment: a preliminary study of personal information organization behaviour. Information Research, 12(2).

[12] Rowlands, I., Nocholas, D., Williams, P., Huntington, P. \& Fieldhouse, M. (2008). Aslib Proceedings: New Information Perspectives, 60, 4, 290-310. DOI 10.1108/00012530810887953.

[13] Chaudhry, A.S. (2013). Information Management Strategies of Knowledge Workers in the Public Sector in Kuwait. Libri: International Journal of Libraries and Information Services, Vol. 63 No. 2. 
[14] Chaudhry, A. S. (2014). Leveraging Personal Networks to Support Knowledge Management in a Public Sector Organisation in Kuwait. Libri: Inerntional Joural of Libraries and Information Services, volume 63, number 2.

[15] Chang, Yun-Ke; Morales Arroyo, Miguel A.; Chum. Chan-Choy; Lim, Tin-Seng; Yuen, Kok-Yuin. (2010). Personal Digital Information Resources Management Behavior. Seventh International Conference on Information Technology, pp.557-562.

[16] Majid, S., San, M.M., Tun, S.T.N. \& Zar, T. (2010). Using Internet services for Personal Information Management. 2nd International Symposium on Information Management in a Changing, 22-24 September 2010. Ankara, Turkey.

[17] Majid, S., Chang, Y., Foo, S., Theng, Y., Mokhtar, I., and Zhang, X. (2013). Strengthening Information Literacy Competencies through Incorporating Personal Information Management Skills. In S. Kurbanoglue et al (Eds). European Conference on Information Literacy. Switzerland: Springer International Publishing, pp. 331337.

[18] O'Farrill, R. T. (2008). Information literacy and knowledge management: Preparations for an arranged marriage. Libri: International Journal of Libraries and Information Services, 58(3), 155-171.

[19] O'Farrill, R. T. (2010). Information literacy and knowledge management at work: Conceptions of effective information use at NHS24. Journal of Documentation, 66(5), 706-733.

[20] Zhang, X., Majid, S., \& Foo, S. (2010). Environmental scanning: An application of information literacy skills at the workplace. Journal of Information Science, 36(6), 719-732. 